\title{
The precipitation characteristics of ISCCP tropical weather states
}

\author{
Dongmin Lee ${ }^{1,2,3}$, Lazaros Oreopoulos ${ }^{2}$
}

George J. Huffman ${ }^{4,2}$,William B. Rossow ${ }^{5}$, and In-Sik Kang ${ }^{3}$

1. GESTAR, University Space Research Association, Columbia, MD, USA

2. Earth Sciences Division, NASA-GSFC, Greenbelt, MD, USA

3. Seoul National University, Seoul, South Korea

4. Science Systems and Applications Inc., Lanham, MD

5. City College and Graduate School, City University of New York, New York, NY, USA

\author{
Submitted to the \\ Journal of Climate \\ December 2011
}

Corresponding author address:

Lazaros Oreopoulos

NASA-GSFC

Code 613

Greenbelt, MD 20771

USA

Lazaros.Oreopoulos@nasa.gov 



\section{Popular Summary}

In order to understand the water budget of the planet it is important to measure the rainfall distribution. We can now achieve relatively good rainfall estimates from satellites over almost the entire planet. Only measuring rainfall amounts is however not enough for understanding the underlying physical processes that determine where, when, and how much rainfall occurs. We must also observe and measure other atmospheric characteristics that are related to rainfall, such as the properties of clouds. In this paper we propose a method that will help us better understand what cloud mixtures the precipitation of the tropical region (covering about half the are of the planet and exhibiting the strongest rainfall intensities) originates from. We achieve this by combining different satellite measurements targeted to rainfall and cloud thickness/height estimations. One of our main findings is that in the tropics about half of the total rainfall comes from one particular type of cloud mixtures, associated with deep storm systems. Surprisingly, our combined datasets indicate that even these clouds are often (about half the time) not precipitating (raining); when they do they tend to precipitate more strongly over ocean than over land, also a somewhat unexpected result given that several measures of storminess are stronger over land. Our results can be used to check whether climate models assign their precipitation in accordance with the observations and to therefore indirectly assess whether predictions of future precipitation in a changed climate are reliable. 


\begin{abstract}
We examine the daytime precipitation characteristics of the International Satellite Cloud Climatology Project (ISCCP) weather states in the extended tropics $\left(35^{\circ} \mathrm{S}\right.$ to $\left.35^{\circ} \mathrm{N}\right)$ for a 10-year period. Our main precipitation data set is the TRMM Multisatellite Precipitation Analysis 3B42 data set, but Global Precipitation Climatology Project daily data are also used for comparison. We find that the most convective weather state (WS1), despite an occurrence frequency below $10 \%$, is the most dominant state with regard to surface precipitation, producing both the largest mean precipitation rates when present and the largest percent contribution to the total precipitation of the tropical zone of our study; yet, even this weather state appears to not precipitate about half the time. WS1 exhibits a modest annual cycle of domain-average precipitation rate, but notable seasonal shifts in its geographic distribution. The precipitation rates of the other weather states tend to be stronger when occuring before or after WS1. The relative contribution of the various weather states to total precipitation is different between ocean and land, with WS1 producing more intense precipitation on average over ocean than land. The results of this study, in addition to advancing our understanding of the current state of tropical precipitation, can serve as a higher order diagnostic test on whether it is distributed realistically among different weather states in atmospheric models.
\end{abstract}





\section{The precipitation characteristics of ISCCP tropical weather states}

2

3

4

19 Corresponding author address:

20 Lazaros Oreopoulos

21 NASA-GSFC

22 Code 613

23 Greenbelt, MD 20771

24 USA

25 Lazaros.Orcopoulosianasa.gov by

$$
\text { Dongmin Lee }{ }^{1,2,3} \text {, Lazaros Oreopoulos }{ }^{2}
$$

George J. Huffman ${ }^{4,2}$,William B. Rossow ${ }^{5}$, and In-Sik Kang ${ }^{3}$

1. GESTAR, University Space Research Association, Columbia, MD, USA

2. Earth Sciences Division, NASA-GSFC, Greenbelt, MD, USA

3. Seoul National University, Seoul, South Korea

4. Science Systems and Applications Inc., Lanham, MD

5. City College and Graduate School, City University of New York, New York, NY, USA

Submitted to the

Journal of Climate

December 2011

26 


\section{Abstract}

27 We examine the daytime precipitation characteristics of the International Satellite Cloud 28 Climatology Project (ISCCP) weather states in the extended tropics $\left(35^{\circ} \mathrm{S}\right.$ to $35^{\circ} \mathrm{N}$ ) for a 10 -year 29 period. Our main precipitation data set is the TRMM Multisatellite Precipitation Analysis 3B42 30 data set, but Global Precipitation Climatology Project daily data are also used for comparison.

31 We find that the most convective weather state (WS1), despite an occurrence frequency below $3210 \%$, is the most dominant state with regard to surface precipitation, producing both the largest 33 mean precipitation rates when present and the largest percent contribution to the total 34 precipitation of the tropical zone of our study; yet, even this weather state appears to not 35 precipitate about half the time. WS1 exhibits a modest annual cycle of domain-average 36 precipitation rate, but notable seasonal shifts in its geographic distribution. The precipitation 37 rates of the other weather states tend to be stronger when occuring before or after WS1. The 38 relative contribution of the various weather states to total precipitation is different between ocean 39 and land, with WS1 producing more intense precipitation on average over ocean than land. The 40 results of this study, in addition to advancing our understanding of the current state of tropical 41 precipitation, can serve as a higher order diagnostic test on whether it is distributed realistically 42 among different weather states in atmospheric models. 


\section{1. Introduction}

44 The role of clouds in the water and energy cycle can not be overstated. Atmospheric heating

45 rates (due to radiative and thermodynamical processes), surface energy budgets (radiative and

46 turbulent), and precipitation rates have strong dependencies on cloud properties, and frequency

47 of occurrence. While the average effect of cloud can be studied in aggregate, grouping the

48 multitude of observed cloud systems into discernible cloud regimes and studying the energy and

49 water budgets associated with them can be a far more useful approach for understanding the

50 potential impact of cloud changes on future water and energy budget distributions. An additional

51 advantage of such a holistic approach is that more physically-based diagnostics to evaluate

52 Global Climate Model (GCM) hydrological and radiative budgets can be formulated.

53 A number of recent studies have focused on the topic of objectively identifying distinct

54 cloud regimes. The criterion commonly used for identifying cloud regimes is the co-variation of

55 cloud location (expressed as cloud top height or pressure) and extinction (expressed as cloud

56 optical thickness or reflectivity). Cloud mixtures exhibiting certain patterns in the co-variation of

57 these quantities can be identified as distinct cloud regimes. The patterns can be identified with

58 either neural network or $k$-means clustering techniques with the latter being generally easier to

59 implement and therefore more popular (Jakob and Tselioudis 2003; Rossow et al. 2005; Zhang et

60 al. 2007; Gordon and Norris 2010; Greenwald et al., 2010). The search for patterns can be

61 performed on either a global dataset of joint height-extinction variations or on distinct climatic

62 zones. The breakdown by climatic zone has the advantage that cloud regime identification can be

63 fine-tuned so that cloud mixtures that may have otherwise been obscured in a larger data set can

64 emerge from a more geographically targeted analysis. It also allows examing (dis)similarities

65 between different parts of the globe with regard to the presence and occurence frequency of 
66 different cloud mixtures. Once the regimes have been identified, a variety of properties that 67 characterize them can be easily compiled.

68 A compelling question is whether distinct roles of cloud regimes in weather and climate 69 can be determined. If the atmospheric conditions under which particular cloud regimes form 70 have indeed identifiable features, it should be possible to associate changes in meteorological 71 conditions with changes in hydrology and energetics through these cloud regimes. Studies along 72 such lines have begun to emerge in recent years. Several previous studies (Jakob et al. 2005;

73 Williams and Webb 2008; Oreopoulos and Rossow 2011; Haynes et al. 2011) have focused on 74 the radiative characteristics of cloud regimes. Other studies have concentrated on precipitation 75 characteristics. For example, Jakob and Schumacher (2008) combined cloud regimes, inferred 76 from International Satellite Cloud Climatology Project (ISCCP, Schiffer and Rossow 1983) 77 cloud retrievals, with collocated precipitation and latent heating data from the Tropical Rainfall 78 Measuring Mission (TRMM) Precipitation Radar in the tropical western Pacific. By compositing 79 TRMM precipitation amount and type into the ISCCP regimes they managed to distinguish 80 between three major precipitation regimes and identify their surface precipitation rates and latent 81 heat profile characteristics. Zhang et al. (2010) defined cloud/precipitation regimes in the tropics 82 from profiles of CloudSat/CALIPSO radar/lidar reflectivities and hydrometeor locations and then 83 compared with the corresponding regimes of a GCM operating in weather forecast mode. 84 Tromeur and Rossow (2008) found for the $\pm 15^{\circ}$ latitude zone that while the most convectively 85 active cloud regime dominated by organized deep convection dwarfs the precipitation rate of all 86 other regimes, the regime representing unorganized convection with much lower average 87 precipitation rate has nearly the same contribution, because it occurs much more frequently. 
In this paper we conduct a more extensive and detailed analysis of the precipitation of

89 tropical $\left( \pm 35^{\circ}\right.$ latitude zone) cloud regimes (henceforth referred to as "weather states" following

90 Rossow et al. 2005 who explain that they are associated with distinct atmospheric conditions; see

91 also Jakob and Tselioudis 2003; Jakob et al. 2005; Gordon and Norris 2010). One of our goals is

92 to confirm that these mesoscale weather states as identified by ISCCP help in the understanding

93 of tropical precipitation characteristics. Specifically, we examine the mean magnitude and range

94 of surface precipitation rate produced by the weather states, their relative contribution to the total

95 precipitation of the tropics, and the geographical distribution of weather state precipitation. We

96 also seek to further clarify the degree to which the most convectively active weather states

97 dominate the tropical precipitation, a topic also investigated by Rossow et al. (2011) with a

98 different analysis approach. Our results are featured in section 4 which is broken into

99 subsections, each highlighting separate important aspects of the precipitation-weather state

100 relationship. We discuss means, geographical variations and frequency distributions of each

101 weather state's precipitation rates, and dependencies on the precipitation data set used. We pay

102 special attention to the strongest precipitating weather state, its seasonal variations and its

103 apparent effects on the precipitation of the other weather states when in close temporal 104 proximity.

105

106 2. Data sets

107 Our study uses three data sources: The ISCCP weather states for the extended tropics

108 (Oreopoulos and Rossow 2011) to identify cloud regimes, and two precipitation products, the 109 TMPA-3B42 (Huffman et al., 2010), and GPCP-1DD (Huffman et al., 2001). 
Rossow et al. (2005) describe how the ISCCP weather state product is generated. Briefly, a

111 search for distinctive patterns is conducted in the joint frequency distributions of cloud top

112 pressure $\left(p_{c}\right)$ and cloud optical thickness $(\tau)$ constructed from individual daytime satellite image

113 pixel retrievals (fields-of-view about $5 \mathrm{~km}$ in size) within $2.5^{\circ}$ regions provided in the

114 International Satellite Cloud Climatology (ISCCP) D1 dataset (Rossow and Schiffer, 1999).

115 Cluster centroids representing specific histogram patterns describing cloud variability are

116 identified using the " $k$-means" clustering algorithm (Anderberg, 1973).

117 A weather state dataset derived as described above is now available for the period 1983-

1182008 between $65^{\circ} \mathrm{S}$ to $65^{\circ} \mathrm{N}$ divided in three geographical zones. This dataset can be downloaded

119 from ftp://isccp.giss.nasa.gov/outgoing/PICKUP/CLUSTERS/data/1983-2008/. Here, we use the

120 data corresponding to the so-called "extended" tropical/subtropical zone between $35^{\circ} \mathrm{S}$ and

$12135^{\circ} \mathrm{N}$, ISCCP dataset D1.WS.ET.dat. This dataset has been previously used by Mekonnen and

122 Rossow (2011) and Oreopoulos and Rossow (2011). The optimal cluster centroids are shown in

123 Fig. 1, while maps of weather state relative frequency of occurrence (RFO) are provided in Fig.

124 2. The weather state indices were assigned according to classical understanding of associated

125 convective activity strength, with indices increasing for the progressively more convectively

126 suppressed weather states. Note that this indexing convention follows Rossow et al. (2005), but

127 is opposite of that of Haynes et al. (2011).

128 The weather state data are jointly analyzed with two precipitation datasets for a 10-year 129 overlapping period from January 1998 to December 2007. One is based on the Tropical Rainfall 130 Measuring Mission (TRMM) Multi-satellite Precipitation Analysis (TMPA) algorithm which 131 seeks to provide a "best" estimate of quasi-global $\left(50^{\circ} \mathrm{S}\right.$ to $\left.50^{\circ} \mathrm{N}\right)$ precipitation from the wide 132 variety of modern satellite-borne precipitation sensors as well as gauge measurements where 
133 feasible. Estimates are provided at relatively fine scales, $0.25^{\circ} \times 0.25^{\circ}$, 3-hourly (Huffman et al.

134 2010). We use the post-processed research product which is based on calibration by the TRMM

135 Combined Instrument (TCI) product and covers the period January 1998 to present. The research

136 product system has been developed as the version 6 algorithm for the TRMM operational

137 product 3B42 (3B42 V.6). Henceforth, we will call this product "TMPA-3B42".

138 The other precipitation product used is the GPCP-1DD version 1.1 precipitation product

139 which was developed to support the Global Precipitation Climatology Project (GPCP)

140 established by the World Climate Research Programme to quantify multi-year global

141 distributions of precipitation. The product provides 1-day (daily) precipitation estimates on a 1-

142 degree grid over the entire globe for the period October 1996 - present. The GPCP-1DD product

143 is a complement to the GPCP Version 2 Satellite-Gauge (SG) combination product (Adler et al.

144 2003). GPCP-1DD uses data from geostationary-satellite infrared sensors to compute the

145 threshold-matched precipitation index (TMPI) and provide precipitation estimates on a $1^{\circ} \times 1^{\circ}$

146 grid at 3-hourly intervals within the $40^{\circ} \mathrm{N}-40^{\circ} \mathrm{S}$ latitude zone. The TMPI sequence of

147 instantaneous 3-hourly estimates are summed to produce the daily value. Estimates outside this

148 latitude zone (not used in this study) are computed based on recalibrated Television Infrared

149 Observation Satellite Operational Vertical Sounder data from polar-orbiting satellites (Susskind

150 et al. 1997). Additionally, the GPCP-1DD product is scaled in both data regions to match the

151 monthly accumulation provided by the SG product which combines satellite and gauge

152 observations at a monthly time scale on a $2.5^{\circ} \times 2.5^{\circ}$ grid.

153

154

155 


\section{Analysis method}

157 The analysis method is fairly straightforward and is based on compositing the precipitation data

158 as a function of weather state. The D1.WS.ET.dat file contains the weather state index in each

$1592.5^{\circ}$ grid cell for every daytime 3 -hour interval. Due to their different temporal and spatial

160 resolutions the two precipitation data sets have to be treated differently in the compositing

161 process. The 3-hour resolution of the TMPA-3B42 data allows temporal matching with the

162 ISCCP weather state data. Spatial matching to the $2.5^{\circ}$ resolution ISCCP weather state data is

163 achieved by taking the mean of all non-missing $0.25^{\circ}$ precipitation data that fall into the $2.5^{\circ}$ grid

164 cell. GPCP data are resampled from $1^{\circ}$ to $2.5^{\circ}$ via spatial interpolation.

165 For each 3-hour time period, the TMPA-3B42 data are segregated for each weather state in

166 order to calculate the state's precipitation statistics. However, something analogous cannot be

167 performed for the daily-averaged GPCP-1DD precipitation data. We therefore pursue two

168 avenues for segregating and compositing GPCP-1DD data: (1) we assign the same daily

169 precipitation rate to all weather states encountered during the daytime period of a grid cell; or (b)

170 we only consider those grid cells for which a single weather state persists during a day's daylight

171 hours and assign the corresponding GPCP-1DD daily precipitation rate (cf. Rossow et al. 2011).

172 Considering the above, only TMPA-3B42 composited precipitation can be characterized as

173 actual daytime (i.e. during sunlit hours) precipitation. Because the temporal matching with the

174 ISCCP weather states can be performed better, most of our analysis relies on TMPA-3B42

175 precipitation data. The availability of GPCP-1DD precipitation rates, even without the temporal

176 resolution of TMPA-3B42, may however still offer insight on certain aspects of weather state

177 precipitation, as we will show below. To construct two precipitation composites that are more

178 comparable, we also segregate TMPA-3B42 precipitation as in method (2) of GPCP-1DD 
compositing, i.e., we consider the daily-averaged TMPA-3B42 precipitation rates of only those grid cells where a single weather state persists during daytime.

As will be seen in the next section, precipitation data that have been segregated by weather state can be analyzed in terms of their range and variability, geographical distributions, relative contributions to the precipitation budget, and other features.

\section{Characteristics of tropical weather state precipitation}

In this section we identify the relative importance of the various weather states to the tropical precipitation budget, examine the degree to which the weather states are hydrologically distinct, investigate whether a weather state's precipitation is affected by the state that temporally adjoins it, examine the sensitivity of the results to the precipitation dataset used, and perform a separate more detailed analysis on the seasonal and geographical precipitation characteristics of WS1, the most convectively intense weather state.

\section{a. Means and geographic distribution of TMPA-3B42 precipitation}

The geographic distribution of the 10-yr mean daytime precipitation rate for each weather state from TMPA-3B42 is shown in Fig. 3. These are mean rates (including zero precipitation) at the time of weather state occurence. It is immediately obvious that ISCCP joint histogram clustering succeeds in isolating the most intensively precipitating weather state, WS1, with its large portion of high optically thick clouds (Fig. 1). WS1's mean precipitation rate indeed dwarfs the precipitation of any other weather state in the tropics with vast regions of the tropical Pacific and Atlantic oceans exhibiting mean annual precipitation rates in excess of $25 \mathrm{~mm} /$ day. There are significant regional differences in WS I precipitation, like smaller rates over the Indian Ocean 
202 and weaker precipitation over land (further discussed further). The mean precipitation rates for 203 the remaining weather states generally decrease monotonically with their assigned index, with 204 WS2 and WS3 producing significant precipitation (albeit always lower than $10 \mathrm{~mm}$ /day on an 205 annual basis) consistent with their implied level of convective activity (convective anvils that 206 often evolve from WS1 convection in the case of WS2, and unorganized less penetrative 207 convection in the case of WS3). From the convectively suppressed states WS4 to WS8 (grouped 208 together in the precipitation frequency histograms of Rossow et al. 2011), WS8 is notable for a 209 stronger precipitation presence over land areas.

210 To gauge the hydrological importance of a weather state in the tropics, the contribution of 211 the weather state to the total precipitation of the entire region is calculated. These results are 212 shown in Fig. 4, as percentage contributions of each weather state to the total grid cell 213 precipitation. Two important points need to be kept in mind for the interpretation of these

214 figures. First, the contribution of each weather state to the total grid cell precipitation is not only 215 a function of the mean precipitation intensity when the state occurs, but also of its frequency of 216 occurrence in the particular grid cell. If for example, one compares the top panel of Fig. 3 with 217 the top panel of Fig. 4 (WS1) there is not much spatial correlation between mean precipitation 218 rate and contribution. This is because areas where WS1 produces large precipitation are often 219 also areas where WS1 rarely occurs. Second, areas where a particular weather state appears to be 220 contributing significantly are not necessarily areas where that state produces significant 221 precipitation. In other words, the fractional contribution of a state may be large, but with a small 222 total grid cell precipitation, the absolute amounts of precipitation involved are small even for the 223 largest weather state contributor. An example of this is WS3 with small precipitation amount 
224 being the largest contributor of precipitation off the west coast of S. America, a generally dry 225 area (Fig. 3).

226 The domain-average annual daytime mean precipitation and fractional contribution of each 227 weather state to the total tropical precipitation from TMPA-3B42 is shown in Fig. 5. To facilitate 228 the interpretation of the fractional contribution, the domain-average annual RFO is also included 229 in the graph. One can see that despite an RFO of only $\sim 6 \%$, WS1 contributes about half of the 230 total precipitation of the $\pm 35^{\circ}$ latitude zone. This is because the mean precipitation rate of $\sim 19$ $231 \mathrm{~mm} /$ day for this state is more than four times higher than the next strongest precipitating weather 232 state (WS2). But WS2, as well as WS3, are still significant precipitation contributors, 233 collectively contributing about $34 \%$ of the tropical precipitation, i.e., about $67 \%$ of the 234 precipitation that does not come from WS1. The most frequent state, WS8, with an RFO $38 \%$ 235 contributes less than $8 \%$ to the tropical precipitation budget because of its $2^{\text {nd }}$ smallest (after 236 WS7) mean precipitation rate of $\sim 0.6 \mathrm{~mm} /$ day.

237 Fig. 6 breaks down the results of Fig. 5 into land and ocean domain averages. A $2.5^{\circ}$ grid 238 cell is defined as "land" when is contains less than $25 \%$ water, "ocean" when it is more that $75 \%$ 239 water and "mixed" in all other cases. According to this convention, in our latitude zone $23.1 \%$ of $2402.5^{\circ}$ grid cells are land, $71.4 \%$ are ocean, and the remaining 5.5\% are "mixed". One striking, and 241 somewhat unexpected finding is that the mean precipitation rate of WS1 is significantly higher 242 over ocean $(21 \mathrm{~mm} /$ day $)$ than over land $(14 \mathrm{~mm} /$ day $)$. This basic result was reproduced when 243 GPCP-1DD data is used in place of TMPA-3B42 (not shown). The finding seems to contradict 244 conventional wisdom about the greater vigor (i.e., stronger updrafts) of continental deep 245 convection compared to oceanic deep convection. One possible explanation is the drier 246 environment of continental convection causing the evaporation of a significant fraction of the 
247 precipitation before it reaches the ground. This phenomenon, discussed by Geerts and Dejene 248 (2005), who found radar reflectivity profiles peaking at high altitude and decreasing toward the 249 ground in Africa, would be captured by the TMPA-3B42 and GPCP-1DD datasets because of the 250 surface gauge rescaling employed. Another possible mechanism for less precipitation reaching

251 the surface over land could be rain being swept in greater amounts out of the convective cores by 252 the stronger updrafts of continental WS1 systems.

253 Fig. 6 also shows that while the ranking of the weather states with respect to their 254 contribution to the total precipitation is not different between ocean and land, the relative 255 importance of the different weather states as contributors to the precipitation budget exhibits 256 some changes compared to the overall values. One can see, for example, that WS1 is a larger 257 fractional contributor to ocean precipitation than land precipitation, that the opposite is true for 258 WS8, and that WS2 and WS3 are more on par in ocean precipitation contribution than in land 259 precipitation contribution. Differences in the relative fractional contribution between land and 260 ocean can come from the combination of changes in mean precipitation intensity and RFO. For 261 WS1 we see that the RFO over ocean and land is about the same (0.062 and 0.065 , respectively) 262 and the main factor making WS1 a larger relative contributor over ocean is mean WS1 263 precipitation being greater in marine grid cells. In the case of WS3, where both the mean 264 precipitation and the RFO are substantially different between land and ocean, but in opposite 265 directions, it appears that the greater RFO over land dominates the fractional contribution.

\section{b. Comparisons between different datasets and compositing approaches}

268 We now examine whether global values of mean precipitation and contribution are similar when 269 daily-averaged GPCP precipitation is composited. Because of the different temporal resolution of 
270 the GPCP dataset, additional assumptions have to be employed for compositing. The comparison

271 between TMPA-3B42 and GPCP-1DD weather state precipitation is shown in Fig. 7. The top left

272 panel of this figure is the same as in Fig. 5, which shows the domain-average daytime mean and

273 contribution to the total precipitation from our "best" compositing method of TMPA-3B42 data

274 that are temporally matched with ISCCP weather state data. The other panels show results using

275 the alternate compositing approaches discussed in section 3, necessitated by the daily-average

276 nature of the GPCP-1DD data set. The upper right panel shows domain average values obtained

277 by assuming that the GPCP-1DD precipitation is constant throughout the day: all weather states

278 identified during the sunlit period of a grid cell are assigned the same value of precipitation, the

279 (spatially interpolated to $2.5^{\circ}$ ) diurnal average provided by GPCP-1DD. The lower left panel

280 shows values obtained using only those grid cells for which the same weather state persists

281 during the day's daylight hours. Presumably, for the grid cells satisfying the single weather state

282 condition, the assumption of constant precipitation rate throughout the entire daytime period is

283 better. Note that because close the International Date Line daylight hours may be split between

284 two UTC days containing GPCP-1DD data, this area is under-represented in this form of 285 conditional compositing. In the lower right panel the TMPA-3B42 are composited the same way, 286 i.e., using the daily-averaged TMPA-3B42 precipitation and only those grid cells with 287 occurences of only one weather state during the entire daytime period.

288 The RFOs are comparable between the two panels that use all weather state data (upper 289 row panels) and the two panels that use only the fraction of grid cells with the same persistent 290 weather state throughout the day (lower row panels). The RFOs of the lower row panels increase 291 relative to those of the upper row panels for the states that have the largest fractions of grid cells 292 with a persistent daytime weather state. This is most notable for WS8 which has an RFO of 
2930.383 when all the grid cells are accounted for, and an RFO of 0.528 when we only consider the 294 grid cells with no diurnal variability of weather state occurrence. Indeed, for WS8 the fraction of 295 grid cells of the latter type is $18.4 \%$, larger than the counterpart fraction of any other weather 296 state. On the other hand, the RFO of (weakly precipitating) WS7 drops from $\sim 0.085$ to 0.039 297 when implementing this screening because only $6.3 \%$ of grid cells (lowest of all weather states) 298 containing WS7 maintain this weather state for the entire daytime period; in other words, WS7 299 rarely persists during the daytime in the tropics. Overall, the fraction of grid cells with a single 300 weather state during daytime is about $13 \%$, i.e., about $87 \%$ of data are discarded to produce the 301 lower two panels of Fig. 7.

302 Contrasting the upper two panels reveals that using the GPCP-1DD data and the constant 303 daytime precipitation assumption leads to a notably different, but not surprising, picture on the precipitation intensity and relative importance of the three most convective states, compared to TMPA-3B42. The precipitation rate of WS1 falls from $\sim 19 \mathrm{~mm} /$ day to $\sim 14.5 \mathrm{~mm} /$ day and the fractional contribution from 0.49 to 0.33 . On the flip side, the mean precipitation rate and 307 fractional contribution of WS2 and WS3 increase: the ratio of WS2 and WS1 fractional 308 contributions increases from 0.32 for TMPA-3B42 to 0.60 for GPCP-1DD, while the ratio of 309 WS3 to WS1 fractional contributions increases from 0.38 to 0.68 . It appears therefore that when 310 WS2 or WS3 are observed in a grid cell on the same day as WS1, the constant daytime 311 precipitation assumption assigns to WS2 and WS3 day-averaged precipitation estimates inflated 312 by the occurrence of WS1 in the hours before or after (this is further examined later). One can of 313 course view this misassignment of precipitation also from the WS1 perspective, with weaker 314 precipitation assigned to WS1 in grid cells where convectively weaker states have also occurred 315 in the same day. Such misassignments seems to be also "benefiting" the convectively suppressed 
316 states WS4 to WS8, making them appear somewhat stronger precipitation producers and 317 contributors according to GPCP-1DD compared to TMPA-3B42.

318 As pointed out earlier, one can attempt to bring the two precipitation data sets on a more 319 equal footing by including in the compositing only the grid cells with a single weather state 320 during daytime. The results from this analysis are shown in the lower two panels of Fig. 7. The 321 domain-average annual precipitation rates and fractional contributions from the two satellite data 322 sets look in this case more similar when partitioned by ISCCP weather state. Some differences 323 remain, such as the different relative contribution strengths of WS2 and WS3 which are closer in 324 GPCP-1DD than TMPA-3B42, but the most important aspect of the analysis, WS1's dominance, has now been restored in GPCP-1DD to the same level as in TMPA-3B42.

The above analysis confirms the significant daytime variations in tropical precipitation indicated by previous studies (e.g., Nesbitt and Zipser 2003). These variations can significantly affect the outcome of compositing a daily-averaged product like GPCP-1DD.

331 So far we have been examining only the mean annual precipitation of the ISCCP weather states either on a domain-average or regional scale. With the aid of cumulative precipitation rate histograms we will now look into the distribution of precipitation rates in order to gain better understanding on the range and variability of a state's precipitation. Rossow et al. (2011) discuss in detail other ways of constructing conditional precipitation histograms and their dependence on 336 spatial gridding.

337 Four sets of cumulative histograms are shown in Fig. 8, where each panel corresponds to 338 the same data set and compositing assumptions as in Fig. 7. The cumulative frequencies are 
normalized relative to the number of each state's RFO. The first bin is considered non-

340 precipitating and includes all precipitation values below $0.048 \mathrm{~mm} /$ day, the lowest precipitating

341 value in the original spatial resolution TMPA-3B42 dataset.

342 Once again, the upper left panel, based on TMPA-3B42 corresponds to the best possible

343 temporal matching between weather state identification and precipitation. The first, perhaps

344 surprising, feature seen in this panel is that even for the strongest precipitating state, WS1, about

345 half the time WS1 is not precipitating according to TMPA-3B42. The frequent occurrence of

346 non-precipitating WS1 cloud systems reminds us that the ISCCP weather states are only

347 statistical descriptions of cloud regimes that encompass a substantial variety of cloud mixtures.

348 These mixtures may include clouds with significantly higher and lower than WS1 centroid

349 average cloud top pressures and optical depths respectively, that are still more closely related to

350 the WS1 cluster centroid than any of the other centroids. A cursory analysis with one year of

351 ISCCP D1 data indicated that the average cloud top pressure and cloud optical thickness of grid

352 cells containing WS1 was $317 \mathrm{hPa}$ and 10.6 when TMPA-3B42 indicated no precipitation and

$353291 \mathrm{hPa}$ and 13.5 when precipitation was detected. This finding suggests significant height and

354 extinction differences between non-precipitating and precipitating WS1's. Variability among

355 tropical WS1 has also been implied in the results shown in Fig. 6 of Oreopoulos and Rossow

356 (2011) showing very wide WS1 shortwave and longwave cloud radiative effect histograms.

357 Finally, some zero precipitation WS1 occurences may be due to space and time mis-matches:

358 TRMM obtains an instantaneous sample within a 3-hour period and so does ISCCP, but they do

359 not necessarily coincide within that time interval time, with separations high as $1-2$ hours

360 possible. Likewise, because the ISCCP data is spatially sampled at $30 \mathrm{~km}$, and TRMM may not 
361 be looking at the same pixels, different areas within the same grid cell may be captured by the 362 two datasets.

363 The fraction of non-precipitating WS1 occurences drops dramatically when daily-averaged 364 precipitation values are used (the other three panels). This indicates that when WS1 appears in a 365 grid cell at some point during daytime it is highly unlikely that no precipitation will be recorded 366 at some other time during the same day. Indeed, regardless of what data set or assumption is used 367 for compositing daily precipitation, there is never a higher than $10 \%$ chance that a grid cell 368 containing WS1 will remain precipitation-free for the entire day.

369 The frequency of non-precipitating cloud mixtures increases rapidly as one progressively 370 moves to the most convectively suppressed weather states. For example, even for WS3, $86 \%$ of 371 occurences are not associated with any precipitation according to TMPA-3B42 (upper left 372 panel). These frequencies are again smaller when daily precipitation averages are composited:

373 the other three panels agree that only $\sim 45 \%$ of grid cells containing WS3 at some point during 374 daytime will maintain zero precipitation throughout the day.

375 At the high end of the precipitation distribution we note from the upper left panel of Fig. 8 376 that while about $26 \%$ of WS1 occurences are associated with rain rates above $24 \mathrm{~mm} /$ day, the 377 corresponding percentage drops to about 7\% for WS2, 4\% for WS 3 and more rapidly therafter to 378 values below $0.5 \%$ for WS5 to WS 8 . This part of the histogram changes less by the details of 379 compositing (s result also found by Rossow et al. 2011). For example, the upper right panel 380 based on GPCP-1DD has counterpart values for WS1-WS3 of $23 \%, 7 \%$ and $3 \%$ indicating that 381 strong precipitation also tends to be persistent. The cumulative histograms of the last four 382 weather states form a group of histogram curves that is clearly distinct from the other weather 
states, also characterized by well-separated histograms. This reinforces the fact that the ISCCP

384 weather state centroids are good classifiers of the various tropical precipitation regimes.

\section{d. Precipitation dependence on weather state transitions}

387 Another approach for assessing precipitation variability within weather states is to examine 388 whether a state's precipitation depends on the weather state that precedes or follows it. 389 Intuitively, one would expect some dependence because a particular state's realization may have 390 features that fluctuate according to what preceded or what follows. For example, a cloud mixture 391 classified as WS3 may have differnt features when it follows WS1 instead of (probably more 392 rarely) WS2.

393 Figure 9 shows the annual-domain averaged precipitation of a weather state as a function of 394 the weather state that either preceded (top panel) or followed (bottom panel). Such an analysis 395 can obviously only be performed with the 3-hourly TMPA-3B42 data set. For all weather states, 396 the mean precipitation rate is stronger when the state is preceded or followed by WS1 (squares 397 enclosed by the red dashed rectangle and the WS1-WS1 square along the diagonal). The 398 frequency with which transitions to or from WS1 happen is, of course, different for each weather 399 state and does not affect the values in the figure which are simply the mean precipitation rates 400 when the state occurs. Interestingly, except for the case it is preceded or followed by itself, WS1 401 exhibits the strongest precipitation when it is preceded or followed by WS8 than any other 402 weather state, including the ones that are convectively stronger. The transition from WS 8 to WS1 403 and vice-versa is however rare (not shown). One other interesting feature seen in the bottom plot 404 is that the mean precipitation of WS2, WS3 and WS4 falls within the same range of 9-12 $405 \mathrm{~mm}$ /day when followed by WS1. This is especially surprising for WS4, which is a rather weakly 
406 precipitating state when the analysis is not conditional on close temporal proximity of WS1. But

407 when WS1 precedes, WS2 precipitates more that WS3 and WS4 (top plot). Because of their

408 lower values, the precipitation characteristics of other combinations of weather state transitions

409 (i.e., squares within the black dashed rectangle) do not merit further discussion here. We do,

410 however, show the geographical distribution of the sum of the precipitation values enclosed

411 within the black and red rectangles in the middle panel of Fig. 10. This is simply the map of the

412 mean precipitation rate originating from all weather states except WS1, i.e., WS2 to WS8. This

413 map should be contrasted with the counterpart maps in the top and bottom panels which shows

414 again mean precipitation rates originating from WS2 to WS8, but this time only considering the

415 cases where WS1 either precedes (top panel) or follows (bottom panel), i.e., the same values

416 used for obtaining the means within the red dashed rectangle of Fig. 9. WS2 to WS 8 are

417 precipitating stronger everywhere when they are in temporal proximity to WS1, and more so

418 when they precede WS1 rather than follow it. These transition results can be explained by the

419 changing weather states representing different parts of the same storm system. The domain-

420 average precipitation rates for the three panels from top to bottom are $8.16,1.56$ and 10.71

$421 \mathrm{~mm} /$ day.

423 e. Seasonal variations of WS1

424 Our analysis so far has clearly demonstrated that WS1 is by far the most important weather state 425 for tropical precipitation. This comes as no surprise, since it simply expresses the fact that deep 426 convection is a major contributor of tropical precipitation. In this subsection we perform 427 additional analysis of WS1 precipitation characteristics, focusing on seasonal variations. The 428 seasonal variations of the other states' precipitation were also examined but are not shown 
429 because both the precipitation rates and their relative seasonal variability are appreciably weaker.

430 From a domain-average perspective, even the WS1 annual cycle of mean precipitation is not 431 particularly strong (Fig. 11), a result also found by Tselioudis and Rossow (2011). The

432 maximum value occurs in June, but is only $\sim 6 \%$ higher than the annual mean; the minimum 433 value occurs in March, but is only $\sim 4.5 \%$ below the annual mean. Seasonal variations in the 434 fractional contribution relative to the annual mean are even lower (2.5\% above annual mean in 435 October and $2.7 \%$ below annual mean in June are the highest deviations). This is because months 436 with relatively high precipitation rates have also relative low RFOs and vice-versa.

437 Even though the seasonal variations of WS1 domain-average precipitation are not strong, 438 geographical distributions vary significantly with season. The 10-year average seasonal daytime 439 precipitation totals (in $\mathrm{mm}$ ) of WS1 are shown in the top four panels of Fig. 12. There are 440 substantial zonal movements of WS1 precipitation in accordance with movements of WS1 441 occurences (shown in the bottom four panels of Fig. 12 as absolute counts). The band of deep 442 convection known as the ITCZ moves northward from DJF to JJA and this is reflected in the 443 northward displacement of WS1 precipitation. WS1 produces the lowest precipitation totals over 444 Africa and S. America in JJA and the highest precipitation totals over south Asia, including India 445 and the bay of Bengal. The eastern equatorial Pacific WS1 precipitation is also stronger during 446 JJA. DJF marks the return of WS1 precipitation south of the equator in Africa and S. America, 447 and is also characterized by high precipitation totals in the South Pacific Convergence Zone and 448 the western part of the maritime continent where WS1 occurence peaks. Thus, while the WS1 449 precipitation totals of the entire geographical zone do not change by much, the zonal and 450 meridional precipitation movements are quite prominent. Overall, the seasonality of tropical 
451 precipitation geographical shifts seems to come primarily from WS1, with other states not 452 exhibiting much geographical motion.

\section{$454 \quad$ 5. Summary and discussion}

455 We provide a comprehensive picture of the relationship between ISCCP weather states (also 456 called cloud regimes by some authors) and precipitation for the entire tropics $\left(35^{\circ} \mathrm{S}\right.$ to $\left.35^{\circ} \mathrm{N}\right)$, 457 thus significantly expanding the limited knowledge from prior studies which were more 458 geographically restricted. Our analysis relies on the concepts of conditional sampling/sorting and 459 composite averaging. By employing these concepts on two widely used merged (satellite and 460 surface) precipitation data sets, TMPA-3B42 and GPCP-1DD we gain insight on how the 461 tropical precipitation budget is partitioned among the various weather states identified by 462 analysis of ISCCP-retrieved cloud properties. We focus primarily on the TMPA-3B42 463 precipitation dataset because it has the same 3-hour temporal resolution as the ISCCP weather 464 states. Because weather states can only be identified during daytime when cloud optical 465 thickness from passive visible observations is available, our findings, based on 10 years of 466 measurements, only apply to daytime precipitation. GPCP-1DD precipitation compositing 467 applies by nature to diurnally-averaged precipitation.

468 We find that the mixture of high and optically thick clouds represented by weather state 469 with index " 1 " (WS1) in the ISCCP data set and considered the most convectively active is 470 associated with almost half the tropical precipitation despite the fact that it occurs only about $6 \%$ 471 of the time. This is because its mean precipitation rate at the time of occurrence is about 19

$472 \mathrm{~mm} /$ day, more than four times higher than the second most active state (WS2) which happens to 473 also have the second highest mean precipitation rate. The presence of WS1 affects the apparent 
474 precipitation of the other weather states: when WS1 occurs in a grid cell before or after another

475 weather state, the precipitation assigned to that state is stronger. It seems therefore that weather

476 states occuring before or after WS1 are affected by its convective progenitors or descendants.

477 But even this weather state appears to be precipitation-free about half the time according to a

478 frequency distribution analysis of TMPA-3B42 precipitation rates. Another feature of WS1 is

479 that it has the strongest seasonal variability of all weather states, still relatively weak on a

480 domain-averaged basis, but with prominent geographical variations. When the precipitation data

481 are composited separately over land and ocean grid cell differences emerge. WS1 precipitates

482 less over land suggesting that updraft strength considerations may be superseded by

483 environmental humidity and its effects on precipitation evaporation. Also, over land the relative

484 contribution of WS3 goes up significantly reaching a value close to half of that of WS1 (over

485 ocean the relative contribution is closer to a quarter of that of WS1).

486 The choice of the precipitation data set used in the compositing affects the results

487 noticeably. The GPCP-1DD precipitation represents the grid cell diurnal average and cannot be

488 combined with ISCCP weather state data available every 3 hours without further assumptions.

489 When the same daily precipitation rate is assigned to every weather state that may occur within

490 the grid cell during sunlit hours, the contrast between the three most convective weather states is

491 tempered. The domain-average precipitation rates and contributions become much more

492 consistent between the two datasets, as might be expected, when most data are discarded in favor

493 of grid cells with a single weather state persisting during daytime. Apparently, for those cases the

494 GPCP-1DD daily average is a much better representation of the state's precipitation. Diurnally

495 averaged precipitation composites cannot capture as well the frequency of non-precipitating 
496 WS1 occurences, revealing that once WS1 appears in a grid cell it very uncommon that the cell 497 will remain precipitation-free for the entire 24-hour period.

498 Since clouds are the most prominent regulators of radiation and precipitation, it is natural to 499 explore in future work the connections between precipitation, radiation, and the state of the 500 atmosphere as a function of cloud regime within the weather state framework. Some work along 501 these lines has already been performed to some extent (e.g., Gordon and Norris 2010;

502 Oreopoulos and Rossow 2011; this work), but the unifying effort that will fully integrate the 503 physical relationships between atmospheric dynamical and thermodynamical states and the 504 budgets of radiation and precipitation into a coherent picture has not yet materialized. Once such 505 an effort is completed, a better foundation on how to conjointly analyze cloud regimes and 506 associated meteorology with energy and water budgets will be available for climate models to 507 capitalize on. This can lead to significant leaps in the quality of model hydrology and energetics.

509 Acknowledgements

510 Lazaros Oreopoulos and Dongmin Lee acknowledge funding from NASA's Modeling Analysis 511 and Prediction program and the CloudSat/CALIPSO Science Team recompetition, both managed 512 by Dr. David Considine. William B. Rossow acknowledges funding from the NASA 513 MEASURES and NEWS programs. We would like to thank A. Del Genio for helpful 514 discussions. 


\section{References}

516 Adler, R. F., and Coauthors, 2003: The Version-2 Global Precipitation Climatology Project

517 (GPCP) Monthly Precipitation Analysis (1979-present). J. Hydrometeor., 4, 1147-1167.

518 Geerts, B. and T. Dejene, 2005: Regional and Diurnal Variability of the Vertical Structure of

519 Precipitation Systems in Africa Based on Spaceborne Radar Data. J. Climate, 18, 893-916.

520 Gordon, N. D. and J. R. Norris, 2010: Cluster analysis of midlatitude oceanic cloud regimes:

521 mean properties and temperature sensitivity. Atmos. Chem. Phys., 10, 6435-6459.

522 Greenwald, T. J., Y.-K. Lee, J. A. Otkin, and T. L'Ecuyer, 2010): Evaluation of midlatitude

523 clouds in a large-scale high-resolution simulation using CloudSat observations. J. Geophys. Res.,

524 115, D19203, doi:10.1029/2009JD013552.

525 Haynes, J. M., C. Jakob, W. B. Rossow, G. Tselioudis, and J. Brown (2011), Major

526 characteristics of Southern Ocean cloud regimes and their effects on the energy budget, $J$.

527 Climate, in press.

528 Huffman, G. J., R. F. Adler, M. Morrissey, D. T. Bolvin, S. Curtis, R. Joyce, B McGavock, J.

529 Susskind, 2001: Global Precipitation at One-Degree Daily Resolution from Multi-Satellite

530 Observations. J. Hydrometeor., 2, 36-50.

531 Huffman, G. J., R. F. Adler, D. T. Bolvin, E. J. Nelkin, 2010: The TRMM Multi-satellite

532 Precipitation Analysis (TMPA). Chapter 1 in Satellite Applications for Surface Hydrology, F.

533 Hossain and M. Gebremichael, Eds. Springer Verlag, ISBN: 978-90-481-2914-0, 3-22.

534 Jakob, C., and C. Schumacher, 2008: Precipitation and latent heating characteristics of the major

535 Tropical Western Pacific cloud regimes. J. Climate, 21, 4348-4364. 
536 Jakob, C., and G. Tselioudis, 2003: Objective identification of cloud regimes in the Tropical

537 Western Pacific. Geophys. Res. Lett., 30(21), 2082.

538 Jakob, C., G. Tselioudis, and T. Hume, 2005: The radiative, cloud, and thermodynamic

539 properties of the major tropical Western Pacific cloud regimes. J. Climate, 8, 1203-1215.

540 Mekonnen, A. and W.B. Rossow, 2011: The interaction between deep convection and easterly

541 waves over Tropical North Africa: A Weather State perspective. J. Climate, 24, 4276-4294.

542 Nesbitt, S. W., and E. J. Zipser, 2003: The Diurnal Cycle of Rainfall and Convective Intensity

543 according to Three Years of TRMM Measurements. J. Climate, 16, 1456-1475.

544 Oreopoulos, L. and W. B. Rossow, 2011: The cloud radiative effects of International Satellite

545 Cloud Climatology Project weather states. J. Geophys. Res., 116, D12202,

546 doi:10.1029/2010JD015472.

547 Rossow, W. B. and R. A. Schiffer, 1999: Advances in understanding clouds from ISCCP. Bull.

548 Amer. Meteorol. Soc., 80, 2261-2288.

549 Rossow, W.B., G. Tselioudis, A. Polak, and C. Jakob, 2005: Tropical climate described as a

550 distribution of weather states indicated by distinct mesoscale cloud property mixtures. Geophys.

551 Res. Lett., 32, L21812.

552 Rossow, W. B., A. Mekonnen, C. Pearl, and W. Goncalves, 2011: Tropical precipitation

553 extremes. J. Climate, submitted.

554 Susskind, J., P. Piraino, L. Rokke, T. Iredell, and A. Mehta, 1997: Characteristics of the TOVS 555 Pathfinder Path A dataset. Bull. Amer. Meteor. Soc., 78, 1449-1472.

556 Schiffer, R.A., and W.B. Rossow, 1983: The International Satellite Cloud Climatology Project 557 (ISCCP): The first project of the World Climate Research Programme. Bull. Amer. Meteor. Soc., 
$558 \quad 64,779-784$.

559 Tromeur, E. and W. B. Rossow, 2010: Interaction of Tropical Deep Convection with the Large-

560 Scale Circulation in the MJO. J. Climate, 23, 1837-1853.

561 Tselioudis, G., and W. B. Rossow, 2011: Time scales of variability of the tropical atmosphere

562 derived from cloud-defined weather states. J. Climate, 24, 602-608.

563 Williams, K. D., and M. J. Webb, 2008: A quantitative performance assessment of cloud regimes

564 in climate models. Clim. Dyn., 33, 141-157.

565 Zhang, Y., S. Klein, G. G. Mace, and J. Boyle, 2007: Cluster analysis of tropical clouds using

566 CloudSat data. Geophys. Res. Lett., 34, L12813, doi:10.1029/2007GL029336.

567 Zhang, Y., S. A. Klein, J. Boyle, and G. G. Mace, 2010: Evaluation of tropical cloud and

568 precipitation statistics of Community Atmosphere Model version 3 using CloudSat and

569 CALIPSO data. J. Geophys. Res., 115, D12205, doi:10.1029/2009JD012006.

570 


\section{$570 \quad$ Figure Captions}

571 Figure 1. Cluster centroids for the 8 weather states of the extended tropics geographical zone

$572\left(35^{\circ} \mathrm{S}\right.$ to $\left.35^{\circ} \mathrm{N}\right)$ derived from ISCCP D1 data. Each plot shows the normalized frequency of 573 occurrence (in $\%$ ) within $p_{\mathrm{c}^{-}} \tau$ bins.

574 Figure 2. The geographical distribution of the relative frequency of occurrence (RFO) of the 8 575 weather states of the extended tropics geographical zone for the period 1998-2007. Values are

576 normalized relative to the total number of weather state occurrences with valid TMPA-3B42

577 precipitation measurements within the geographical area for this period.

578 Figure 3. Geographical distribution of the $10-y r$ mean precipitation rate $(\mathrm{mm} /$ day) for each of 579 the 8 extended tropics weather states.

580 Figure 4. Geographical distribution of the fractional contribution to the total 10-yr grid cell 581 precipitation rate of each weather state.

582 Figure 5. Domain-average values of the mean precipitation rates and fractional contributions

583 shown in Figs. 3 and 4. Also included is the domain-average RFO of each weather state.

584 Figure 6. As in Fig. 5, but when TMPA-3B42 precipitation is aggregated separately over ocean 585 (left) and over land (right).

586 Figure 7. (upper left panel): As in Fig. 5; (upper right panel): as the upper left panel, but using 587 GPCP-1DD precipitation rates, assumed constant throughout the day; (lower left panel): as the 588 upper right panel, but using only those grid cells with the same weather state occurring during 589 daytime; (lower right panel): as the upper left panel, but with precipitation diurnally averaged for 590 those grid cells with the same weather state persisting during daytime. 
591 Figure 8. Cumulative histograms of precipitation rate for each weather state for the precipitation 592 datasets and compositing assumptions used in Fig. 7.

593 Figure 9. Mean TMPA-3B42 precipitation rate of each each weather state (with "0" designating 594 cloud-free $2.5^{\circ}$ cells, and grey squares indicating non-existent combinations) at time $T$ as a 595 function of either the weather state 3 hours earlier, $T-3 \mathrm{~h}$ (top) or 3 hours later, $T+3 \mathrm{~h}$ (bottom). 596 The values within the dashed red rectangle of the upper (lower) panel come from the same 597 precipitation data used for the top (bottom) panel of Fig. 10. The black dashed rectangles contain 598 means from precipitation data used in the middle panel of Fig. 10.

599 Figure 10. (middle): Geographical distribution of mean total (combined) daytime precipitation 600 rate from TMPA-3B42 of weather states 2 to 8; (top): same as the middle panel, but when the 601 weather state occuring three hours earlier is WS1; (bottom): same as the middle panel, but when 602 the weather state occuring three hours later is WS1. The domain average values are 1.56, 8.16, 603 and $10.71 \mathrm{~mm} /$ day, respectively. These panels show the geographical distribution of the sum of 604 the means highlighted in the black and red dashed rectangles of Fig. 9, as explained in the 605 caption of that figure.

606 Figure 11. 10-yr mean annual cycle of WS1 TMPA-3B42 precipitation when present, fractional 607 contribution to domain precipitation, and RFO.

608 Figure 12. Geographical distribution of the yearly average seasonal precipitation total (in $\mathrm{mm}$ ) 609 for WS1 (top four panels) and the average number of WS1 occurrences (bottom four panels). 
610
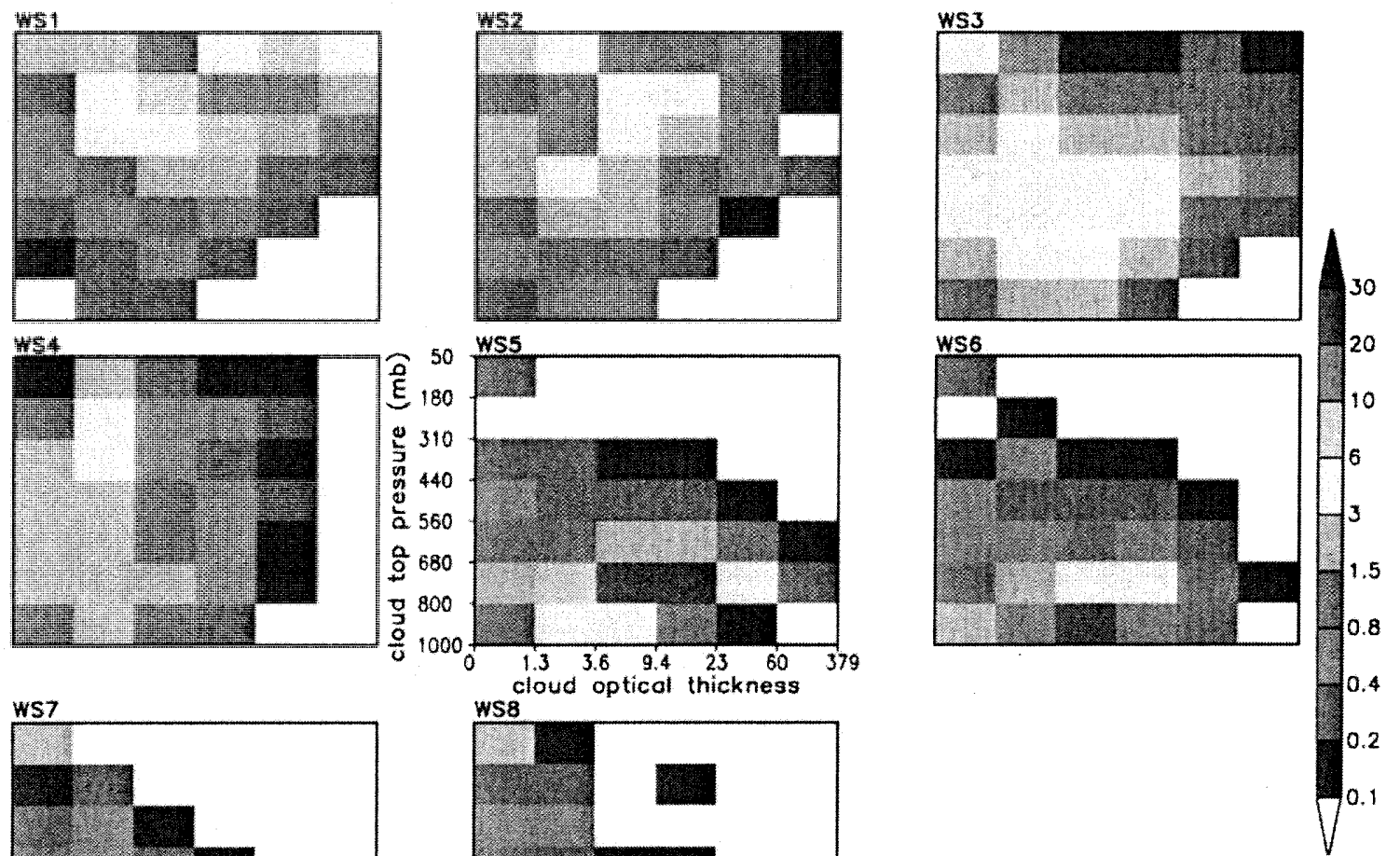

611

wS7

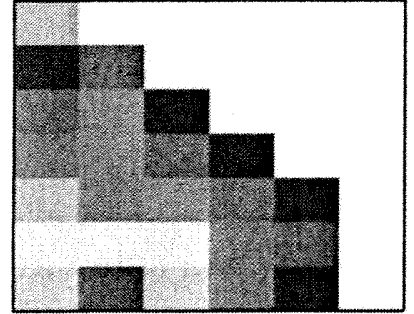

WS8

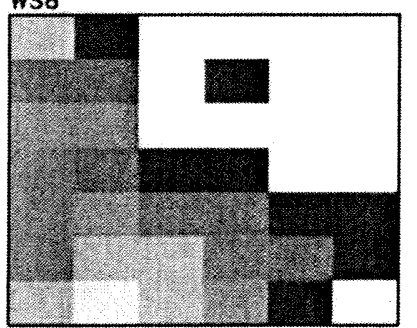

612 Figure 1

613 


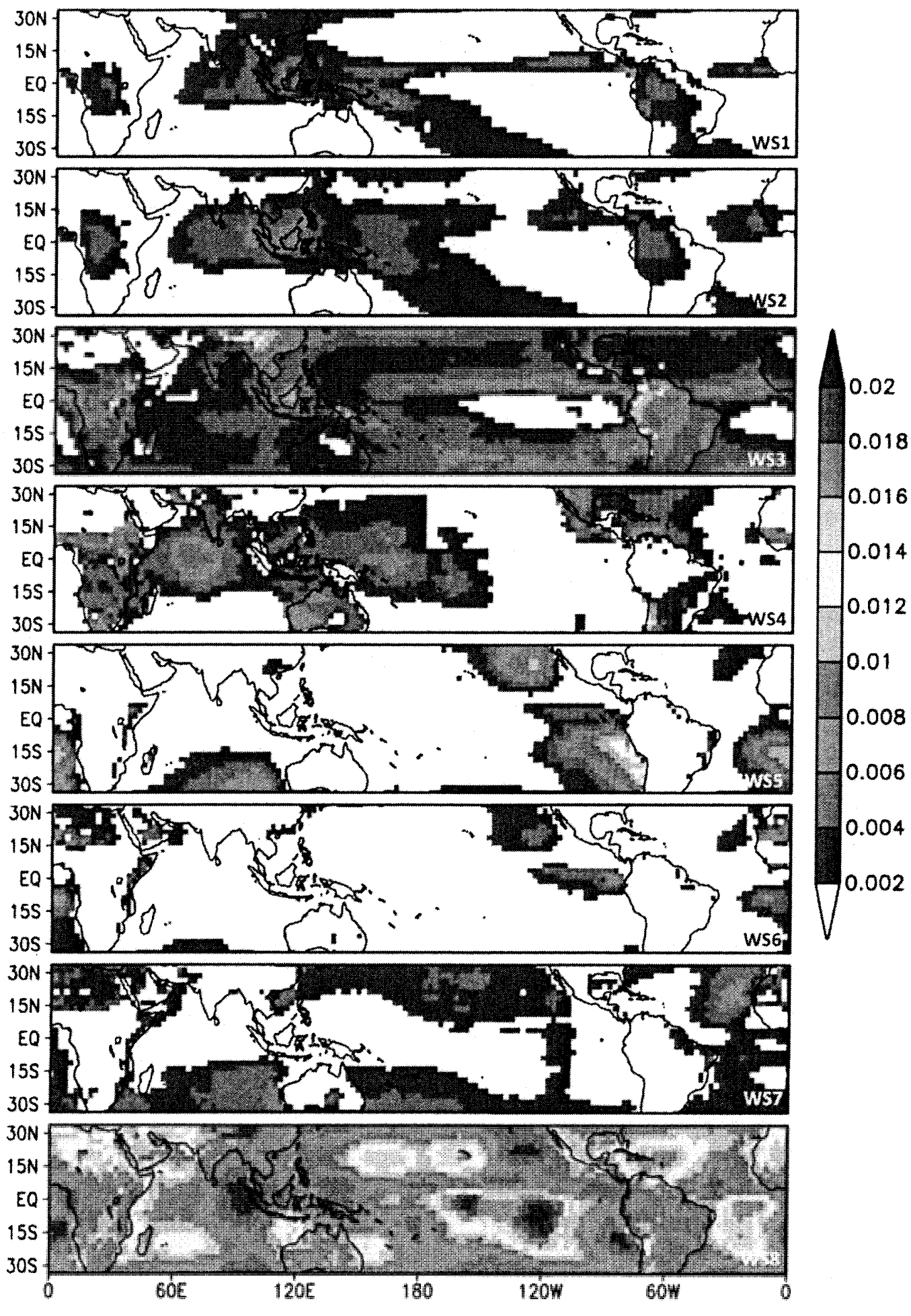

614 Figure 2 


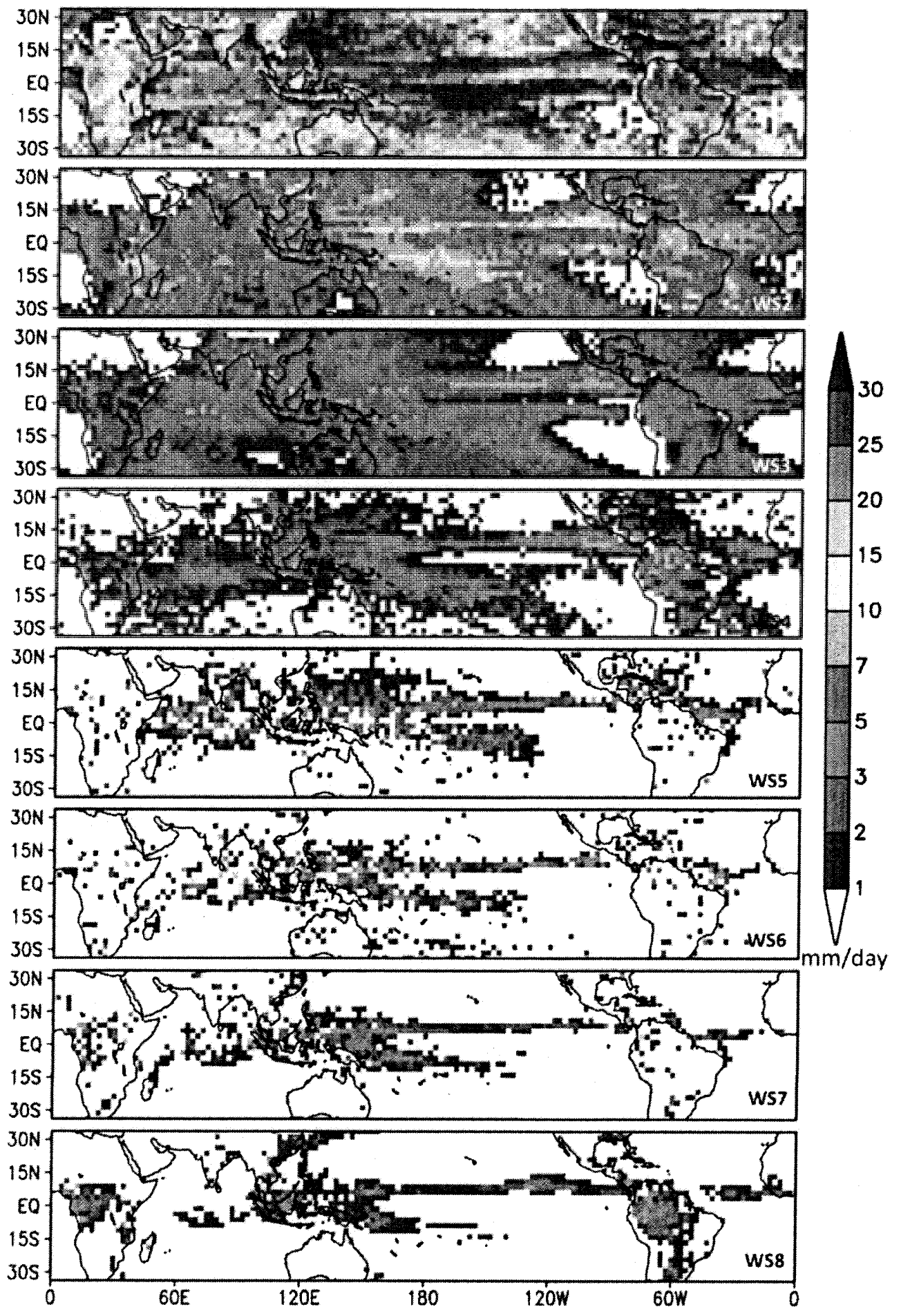

615

$616 \quad$ Figure 3 


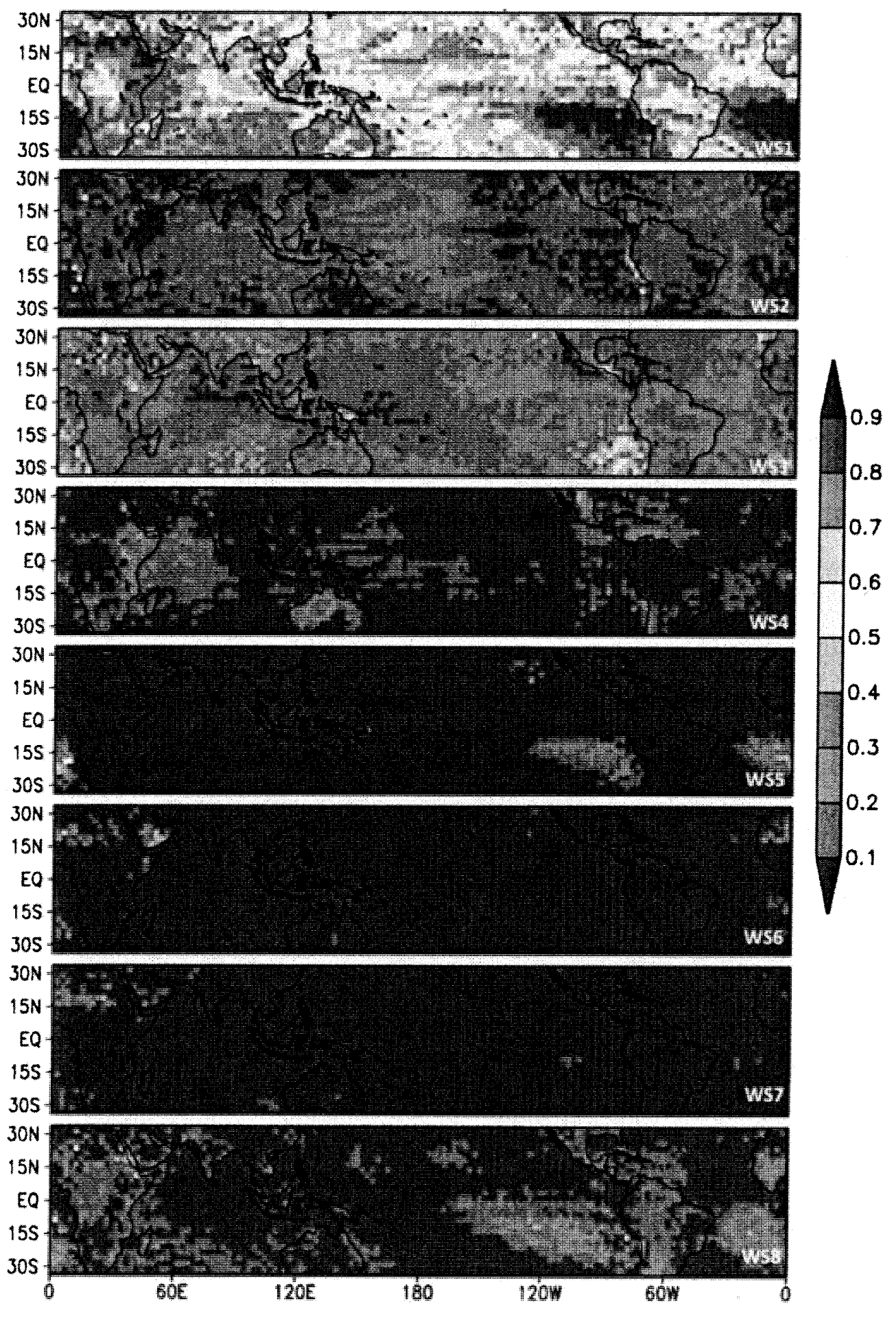

$618 \quad$ Figure 4 


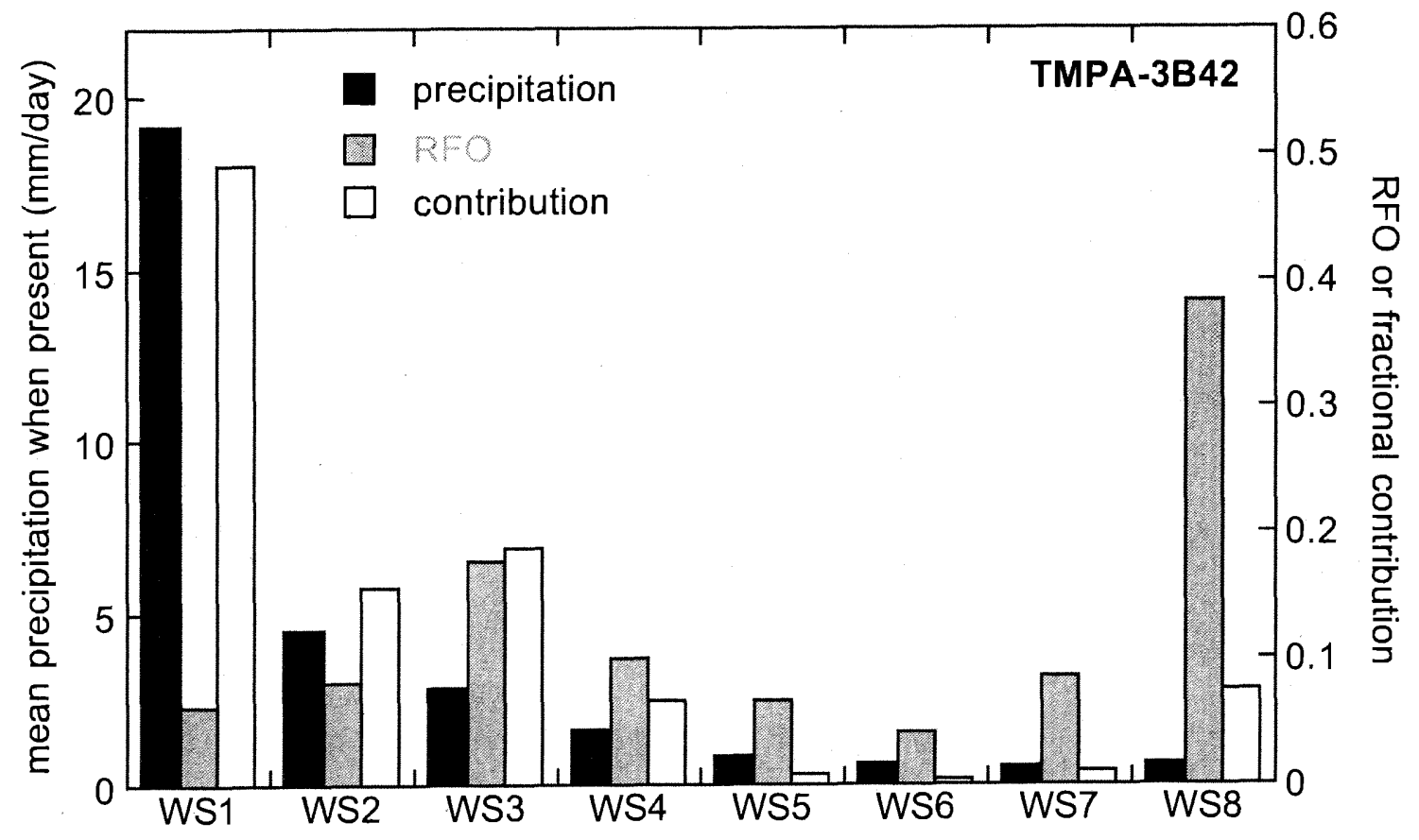

\section{Figure 5}



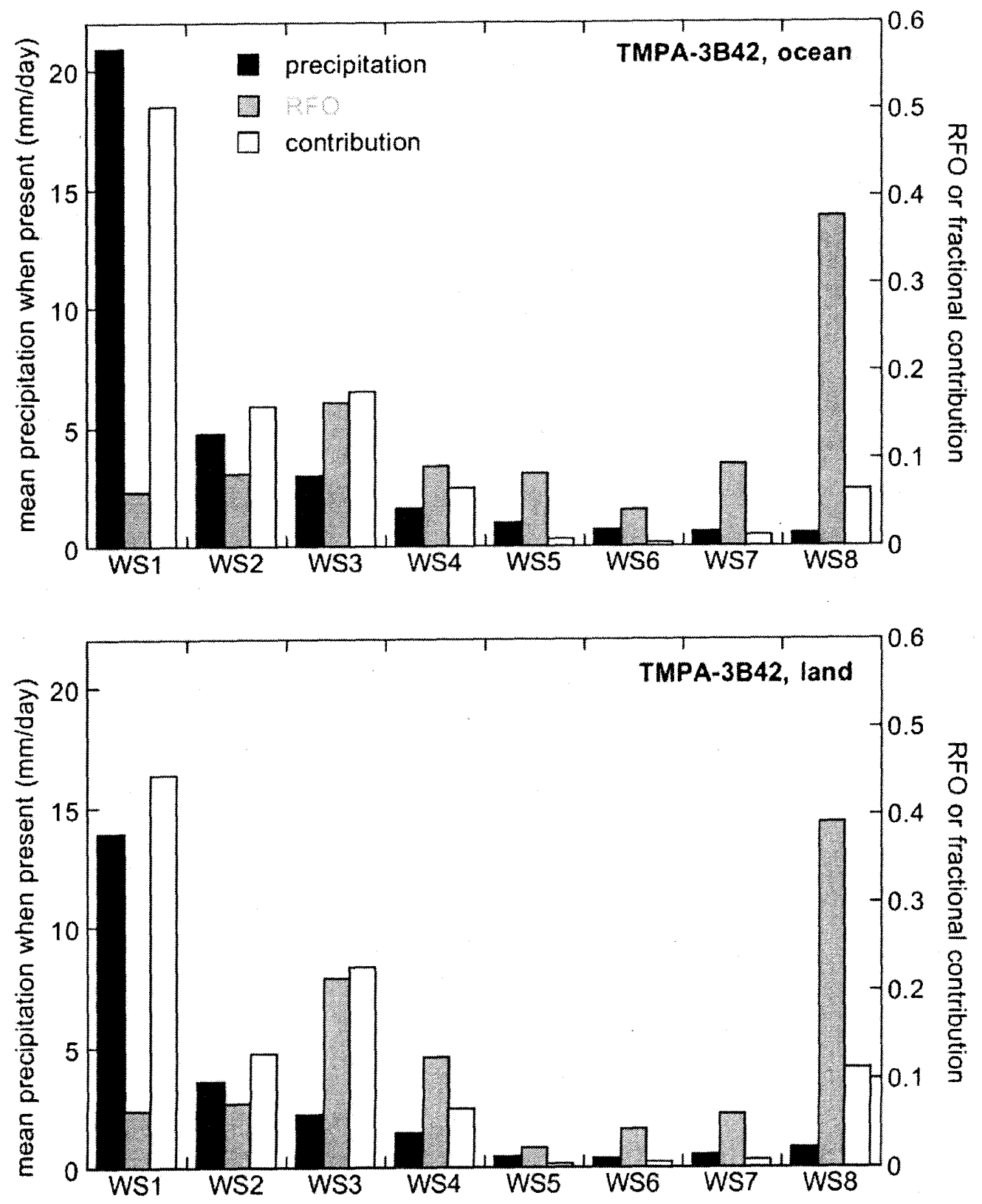

626

$627 \quad$ Figure 6

628 

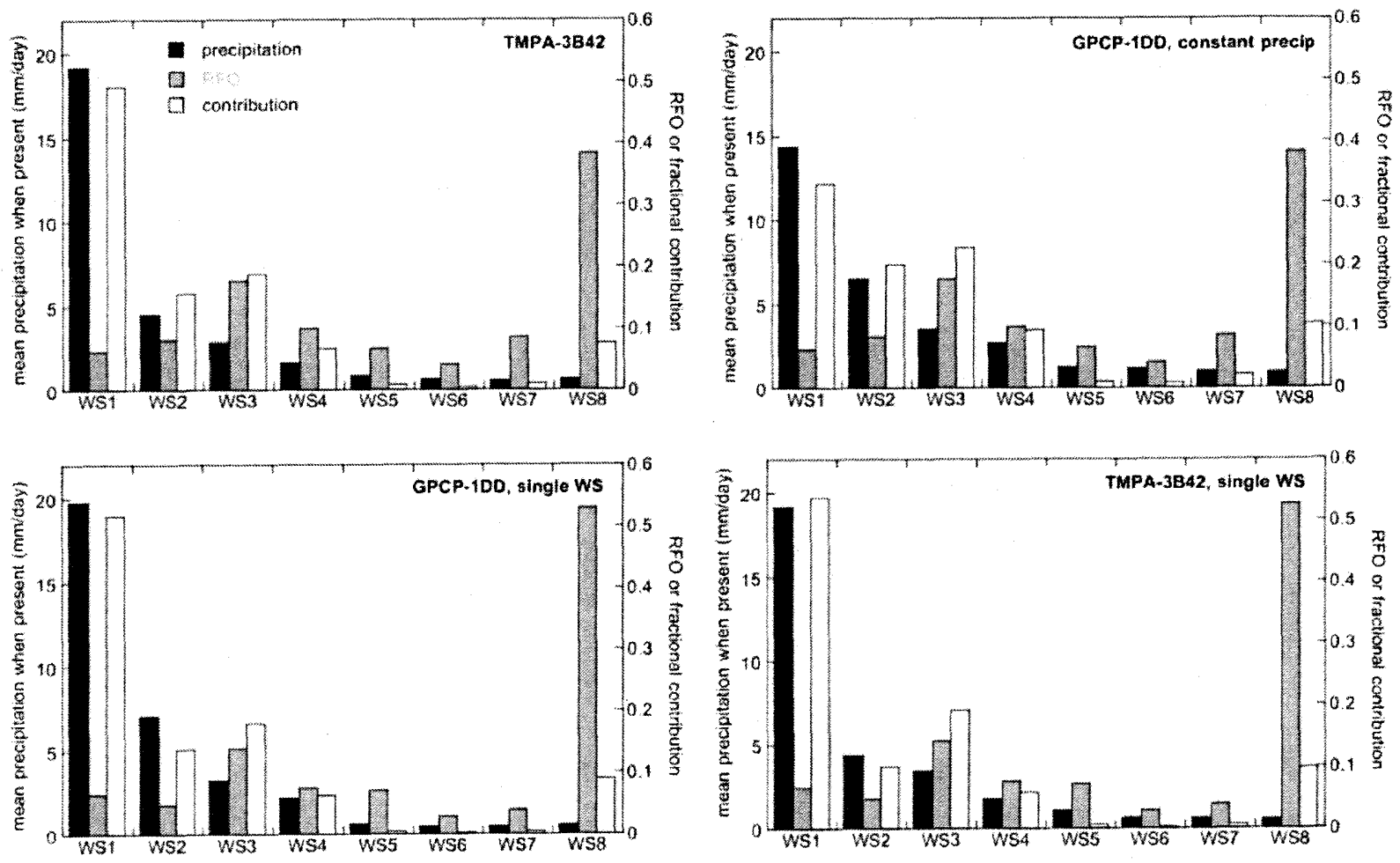

631

$632 \quad$ Figure 7

633 

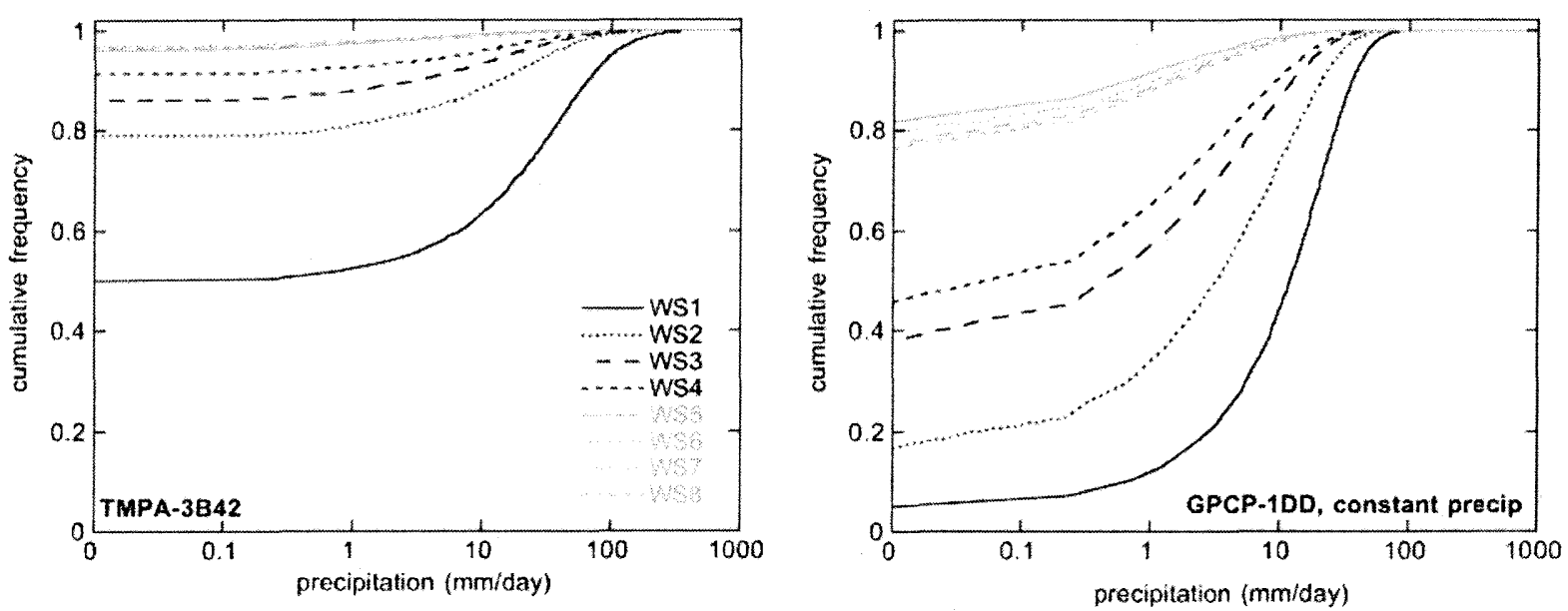

636
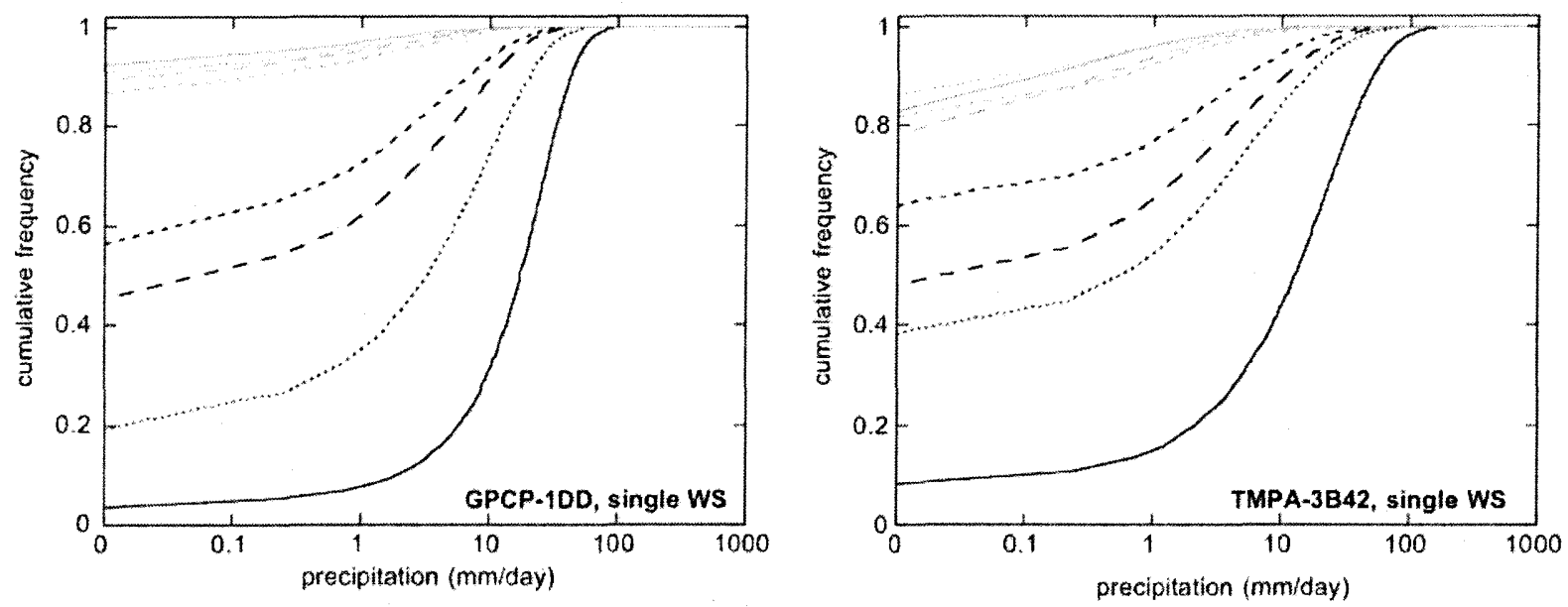

\section{$637 \quad$ Figure 8}

638 

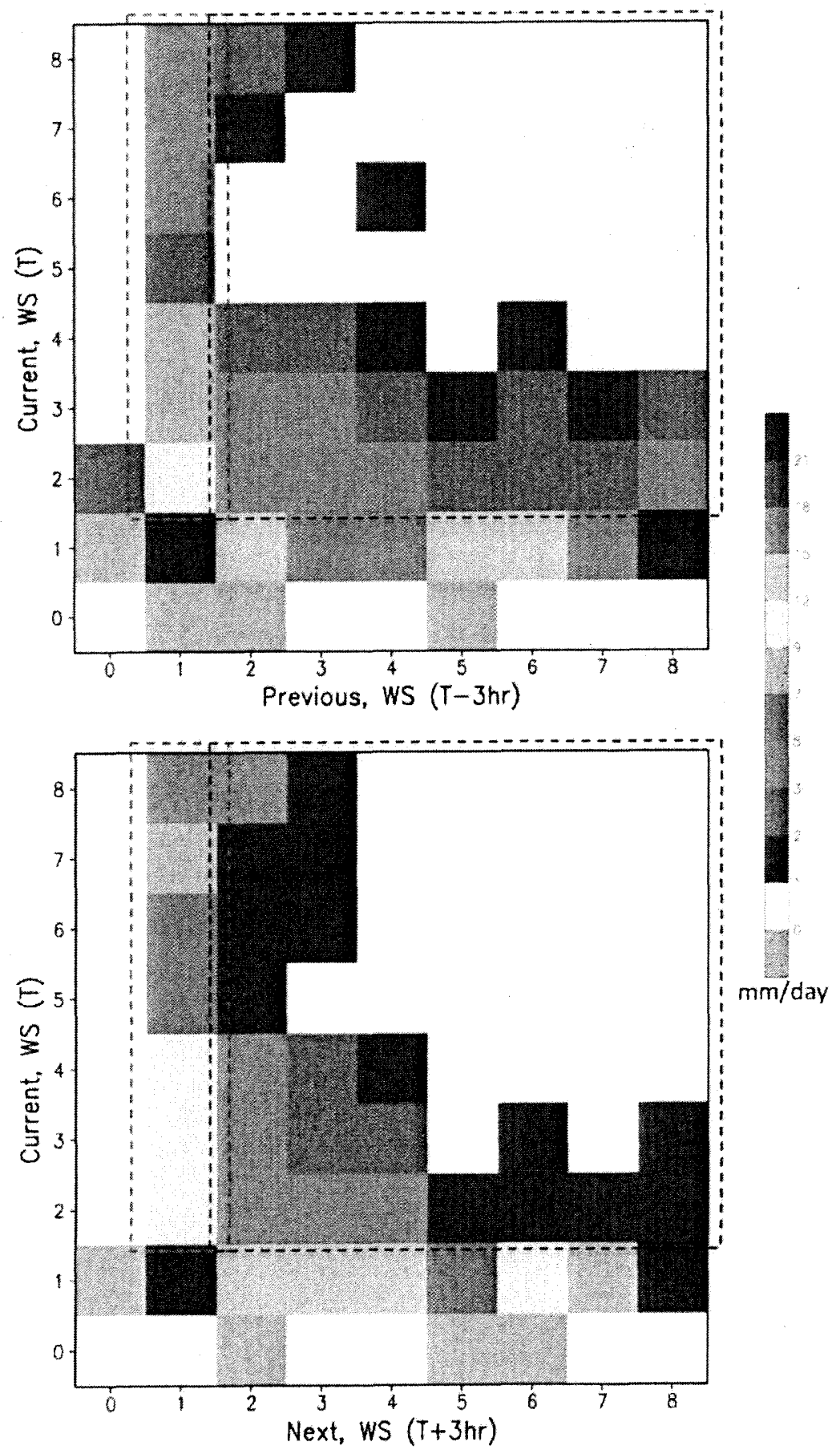

638

$639 \quad$ Figure 9 


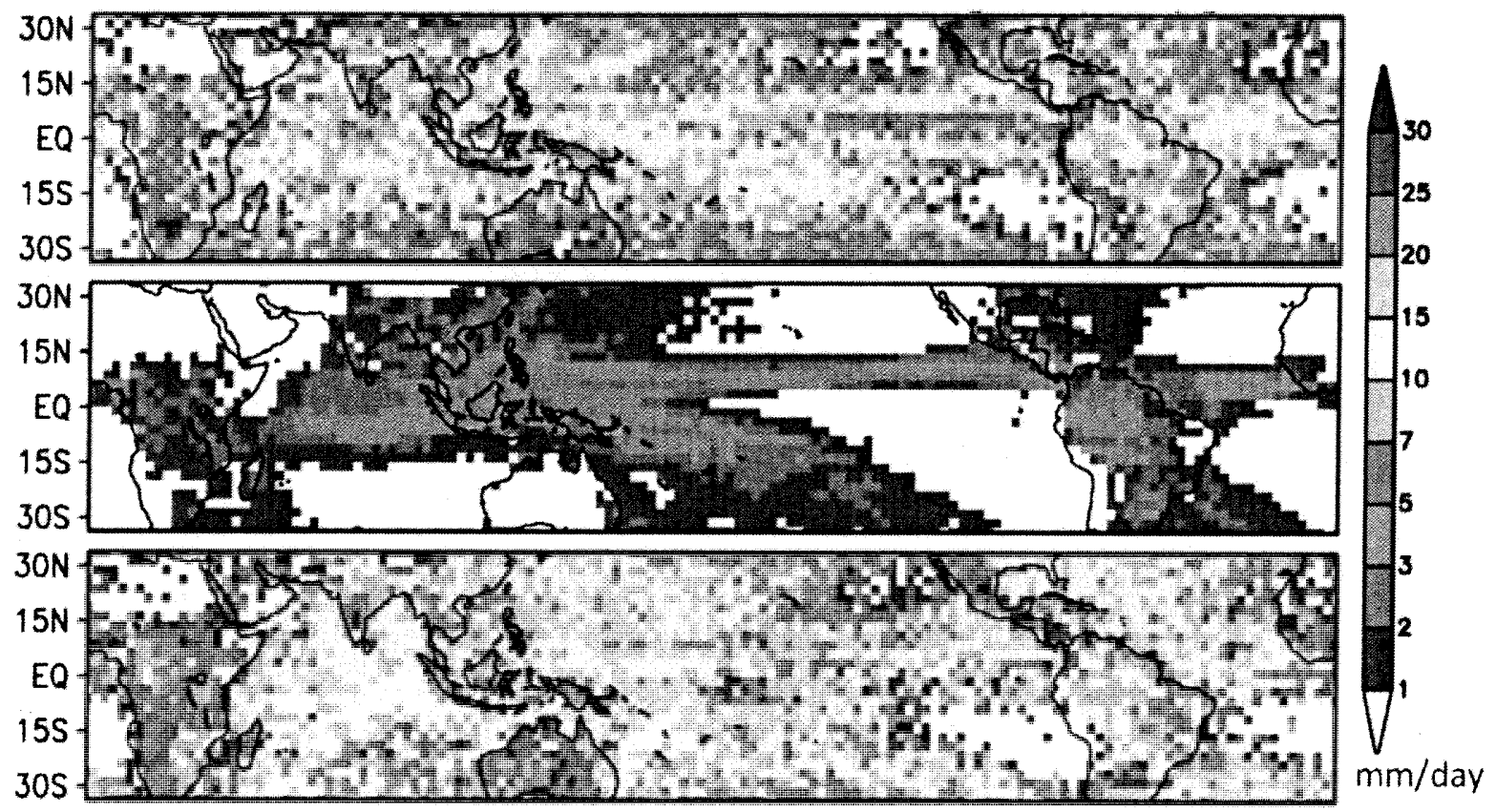

645 Figure 10

646 
646

647

648

649

650

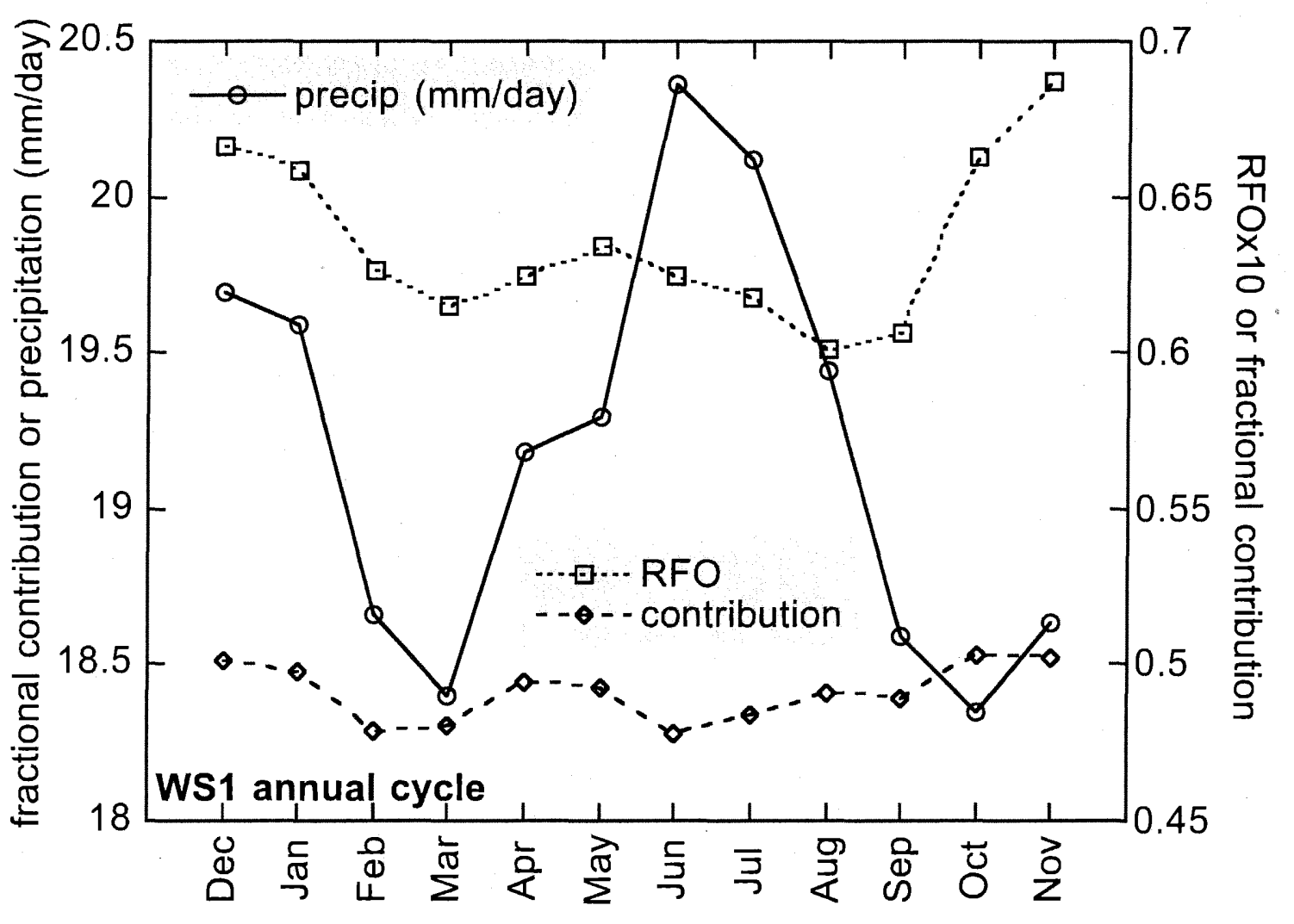

$651 \quad$ Figure 11 

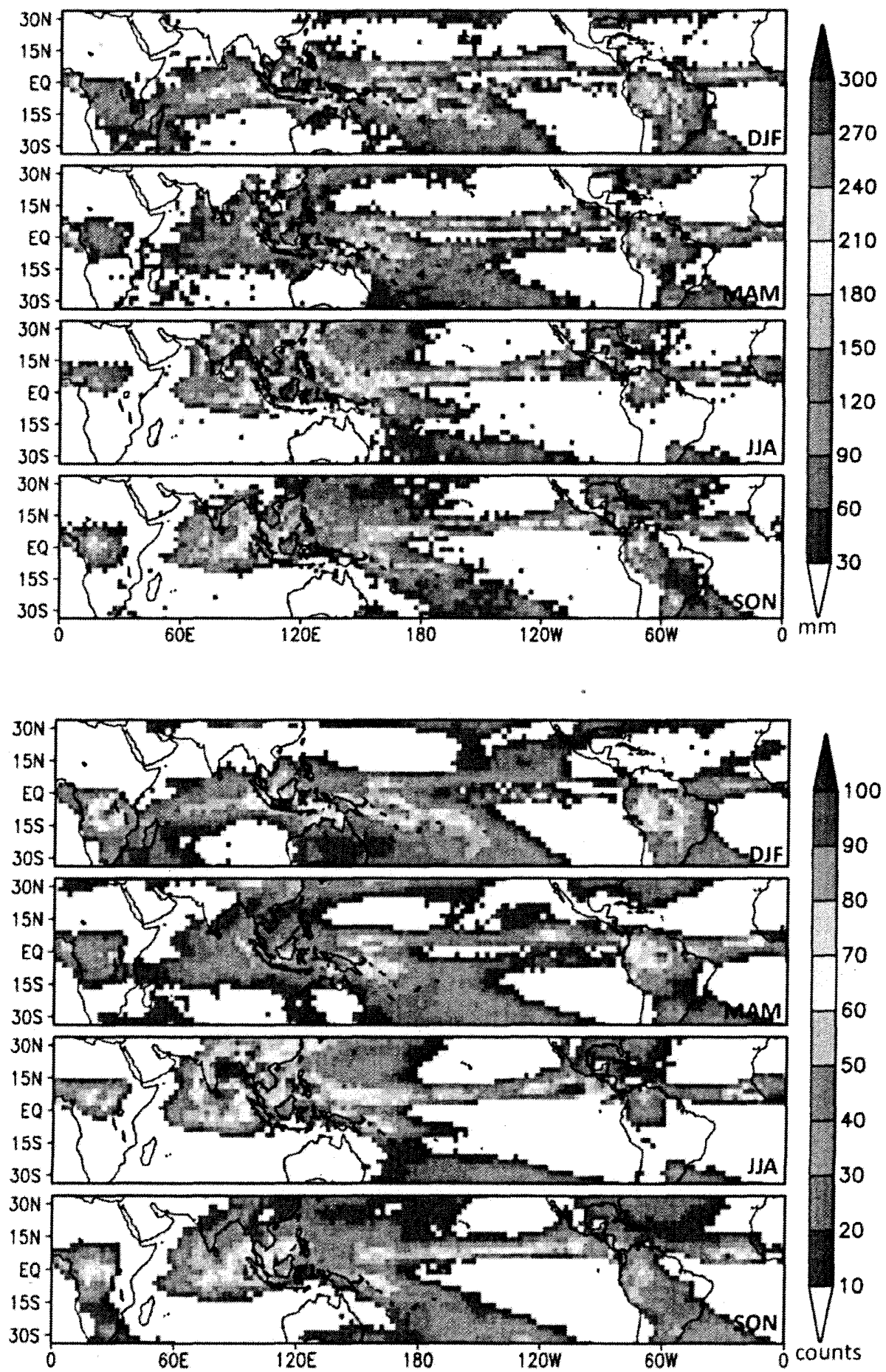

$653 \quad$ Figure 12 